\title{
"An analytical study on medal tally of top ten countries in 2012 Olympic Game according to MAKA ranking system"
}

\author{
Abhinav Bhatt ${ }^{1}$, Sandeep Dabas ${ }^{1}$, Hitesh Tyagi ${ }^{1}$, Dr. J.P. Sharma ${ }^{1}$ \\ H.N.337/A Sarsawti Calony Near Buria Chowk Jagadhri (Yamunanagar) (Haryana)
}

\section{Introduction}

\section{Ancient Olympic Games}

The origin of the ancient Olympic Games is lost the midst of pre-history, but for many centuries they were only a festival of the Greek people. The Games were first held in honour of the Greek God, Zeus in 776 $\mathrm{BC}$ in the plain of kingdom of Elis, nestled in lush valley between the Alpheus River and Mount Kronion, 15 $\mathrm{km}$ from the Ionian Sea. The Olympiad celebrated that year was considered as the first and was used to date subsequent historic events.

\section{Modern Olympic Games}

The revival work of the Games was undertaken by Baron Pierre de Coubertin nearly 1,500 years after the last of the ancient Games. He was born into a family of Italian origin which had settled in France. It was on November 25, 1892, during a conference at Sorbonne about the history of physical exercises, that he first pronounced those famous six words in public "The Restoration of the Olympic Games". He said that the games would ennoble and strengthen amateur sports, to give them strength and lasting quality for an essential role in the world of modern education.

\section{Ranking Systems}

As the IOC does not consider its sorting of nations to be an official ranking system, various methods of ranking nations are used.

\section{Medal Count Ranking}

The gold first ranking system described above is used by most of the world media, as well as the IOC.

\section{Demographic Ranking}

Another ranking system in use is the per-capita ranking, where the number of medals is divided by the population of the country. This does not take into account the fact that every country is limited in the number of participants they can send per event, sometimes as few as one athlete per event, including one team in team events.

\section{Weighted Ranking}

Systematic rankings based upon a weighted point system with the most points awarded to a gold medal have also been devised. They have been popular in some places at some time but none of them have been adopted on a large scale.

\section{Controversies}

Thousands of athletes from around the world gathered to compete in the Olympic Games, the most prestigious of all multi-sport international competitions. Hypothetically, country A's athletes could win 10 gold's and no silver or bronze medals whereas country B's athletes might come away with 9 gold's, 25 silvers, and 25 bronzes. Who can legitimately argue that country A enjoyed more medal success than country B did?

\section{Introduction Of "Maka"}

Government of India provides financial and other assistance to Universities through Association of Indian Universities (AIU) for conducting and participating in national and International tournaments, for coaching and training of athletes of University teams with a view to broad basing and integrating sports and physical fitness in colleges and universities. Government of India instituted 'Maulana Abul Kalam Azad (MAKA) Trophy' award in 1956-57. 


\title{
Method Of "Maka"
}

Based on the level of competitions and prioritization of sports in the changed scenario, various national and international competitions/championships and Inter-University tournaments have been regrouped for computation of marks for the purpose of selection of MAKA Trophy award as follows:

\author{
1. Categories Of Tournaments: \\ Category - A-I \\ 1. Olympic Games \\ 2. World Championships \\ 3. World Cups \\ 4. Davis Cup \\ 5. Thomas Cup \\ 6. Uber Cup \\ 7. Para Olympic Games \\ 8. Winter Olympic Games
}

\section{MARKS CRITERIA:}

2.1 National and International Competitions (Team \& individual events):

Upon securing 1st, 2nd, 3rd and 4th position in team/individual events, the University concerned will get the following marks depending upon the category of event.

\section{Stetment Of The Problem}

The purpose of the study is to "An analytical study on medal tally of top ten countries in 2012 Olympic Game according to MAKA ranking system”.

Objectives Of The Study

The objectives of the study were to analyze and compare different countries on the basis of their:

$>$ Gold first method

$>$ MAKA ranking method

\section{Hypothesis Of The Study}

Hypothesis is a tentative testable answer to question arising in one's mind. So according to the need of the research it was be hypothesized that there would be change in the medal tally in the ranking of top ten countries of the Olympic games 2012, if they are ranked according to the MAKA ranking system.

\section{Delimitions Of The Study}

The present study was delimited to the following aspects:

1. The study was delimited to summer Olympic Games only.

2. The study was further delimited to the Olympic Game of the year 2012-13.

\section{Limitations Of The Study}

The present study was limited to the following aspects:

1. Some of the secondary sources of the data used for gathering the required information were considered as one of the limitation of the study.

2. Time constraints in conducting the present researcher work were one of the limitations of the study.

\section{Significance Of The Study}

1. The result of this is very helpful in the future planning, selection and organization of training for sports participation of Olympic Game etc.

2. It also forms a base for future studies.

3. Similar study may also be conducted on Commonwealth Games, Asian Games, and National Games.

\section{Review of Related Literature}

Mark J. Dixon, Stuart G. Coles (1996) found in his study parametric model is developed and fitted to English league and cup football data from 1992 to 1995 . The model is motivated by an aim to exploit potential inefficiencies in the association football betting market, and this is examined using bookmakers' odds from 1995 to 1996 . The technique is based on a Poisson regression model but is complicated by the data structure and the dynamic nature of teams' performances. Maximum 
likelihood estimates are shown to be computationally obtainable, and the model is shown to have a positive return when used as the basis of a betting strategy ${ }^{1}$

\section{Procedure And Methodology}

The present study has been designed to analyze the medal tally of top ten countries in Olympic Games 2012 according to the MAKA trophy ranking system. The design has been carefully formulated and systematically presented and explained in this chapter.

\section{Sources Of The Data}

The data for the present work had been collected from the following primary and secondary sources:

\section{Primary Sources:}

A primary source of the data is one which contains direct or firsthand information. It may be in the form of direct reporting or direct recording of experience in the shape of a book or memoir.

$>$ Official records: Annual reports, published material, official documents

$>$ Websites

$>$ Published material: Authors of books, journals and articles

$>$ Printed material: reference books.

$>$ Reviews, abstracts thesis and articles.

$>$ Published material: newspaper, magazine

\section{Selection of The Variables}

The researcher has extensively reviewed the literature available on medal tallies of different country in Olympic Games 2012. Keeping in mind the objectives of the present study following variables have been selected.

\section{Gold first ranking system \\ MAKA ranking system}

\section{Collection Of The Data}

Data was collected from the selected primary sources like official documents, recordings, websites, publications, and secondary sources like books, magazines, newspaper etc. Table A represents the top ten nations and number of medals in the Olympic Games held in 2012.

Table III.1

Top Ten Countries and Number of Medal in the 2012 Olympic Games.

\begin{tabular}{|l|l|l|l|l|l|}
\hline Rank & NOC & Gold & Silver & Bronze & Total \\
\hline 1 & $=$ United States (USA) & 46 & 29 & 29 & 104 \\
\hline 2 & China (CHN) & 38 & 27 & 23 & 88 \\
\hline 3 & Great Britain (GBR)* & 29 & 17 & 19 & 65 \\
\hline 4 & Russia (RUS) & 24 & 26 & 32 & 82 \\
\hline 5 & South Korea (KOR) & 13 & 8 & 7 & 28 \\
\hline 6 & Germany (GER) & 11 & 19 & 14 & 44 \\
\hline 7 & France (FRA) & 11 & 11 & 12 & 34 \\
\hline 8 & Italy (ITA) & 8 & 9 & 11 & 28 \\
\hline 9 & Aungary (HUN) & 8 & 4 & 6 & 18 \\
\hline 10 & Australia (AUS) & 7 & 16 & 12 & 35 \\
\hline
\end{tabular}

${ }^{1}$ Mark J. Dixon, Stuart G. Coles -“Modelling Association Football Scores”,http://www.scibet.com/articles/ Vol.33,p.67,(1996). 


\section{Analysis Of Data}

In order to analyze data statistically, the data for the study was tabulated in Descriptive tables. In order to illustrate the observations on the above tables, pie diagrams, bar diagrams, have also been presented.

\section{Findings And Results Of The Study}

The researcher was interested to study the ranking system in Olympic Games 2012 according to the MAKA ranking method. In order to achieve the above purpose, the data collected as explained in chapter III has been analyzed to discuss critically the finding and result and test the hypothesis constructed for the present study.

Fig.IV.1: Medal Tally of USA Individual Game Chart in Olympic 2012

\section{According to Gold First Method Ranking Top Ten Countries Rank Chart}

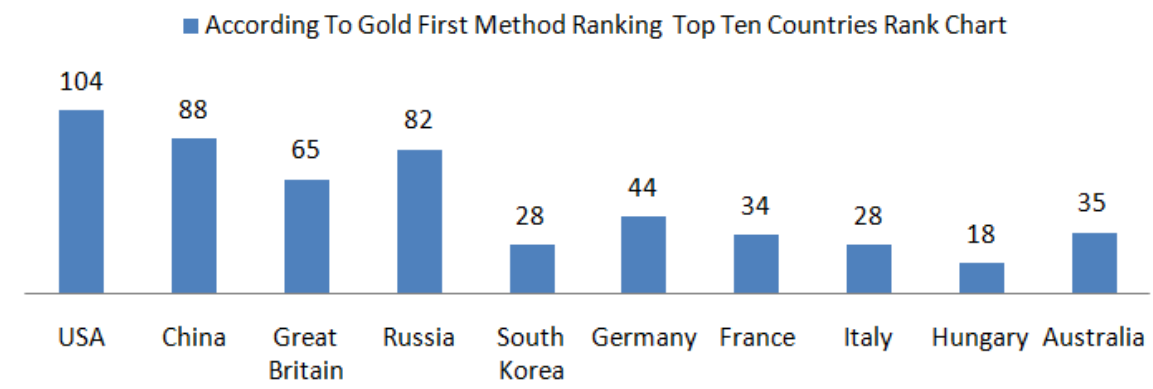

\begin{tabular}{|c|c|c|c|c|c|}
\hline $\begin{array}{l}\text { Rank } \\
\text { ACCORDING } \\
\text { TO GOLD } \\
\text { FIRST } \\
\text { METHOD } \\
\end{array}$ & $\begin{array}{l}\text { OLYMPIC RANKING } \\
\text { TOP TEN COUNTRY } \\
\text { NAME }\end{array}$ & $\begin{array}{l}\text { MAKA RANKING } \\
\text { POINTS OF COUNTRY } \\
\text { INDIVISDUAL AND } \\
\text { TEAM GAMES }\end{array}$ & $\begin{array}{l}\text { ACCCORDING TO } \\
\text { MAKA RANKING } \\
\text { SYSTEM TOTAL } \\
\text { POINT OF } \\
\text { COUNTRY }\end{array}$ & $\begin{array}{l}\text { New } \\
\text { Rank }\end{array}$ & $\begin{array}{l}\text { NEW RANKING } \\
\text { ACCORDING TO } \\
\text { MAKA RANKING } \\
\text { SYSTEM }\end{array}$ \\
\hline 1 & United States (USA) & $30700+13000$ & 43700 & 1 & United States (USA) \\
\hline 2 & China $(\mathrm{CHN})$ & $28600+8325$ & 36925 & 2 & China $(\mathrm{CHN})$ \\
\hline 3 & Great Britain (GBR)* & $17300+10150$ & 27450 & 3 & Russia (RUS) \\
\hline 4 & ssia (RUS) & $26400+5950$ & 32350 & 4 & Britain (GBR)* \\
\hline 5 & South Korea (KOR) & $8800+3250$ & 12050 & 5 & Germany (GER) \\
\hline 6 & Germany (GER) & $11300+6250$ & 17550 & 6 & Australia (AUS) \\
\hline 7 & France (FRA) & $9900+3825$ & 13725 & 7 & \\
\hline 8 & Italy (ITA) & $7600+3400$ & 11000 & 8 & $: 0 \%$ \\
\hline 9 & Hungary (HUN) & $5600+1850$ & 7450 & 9 & (ITA) \\
\hline 10 & Australia (AUS) & $6900+7075$ & 13975 & 10 & Hungary (HUN) \\
\hline
\end{tabular}




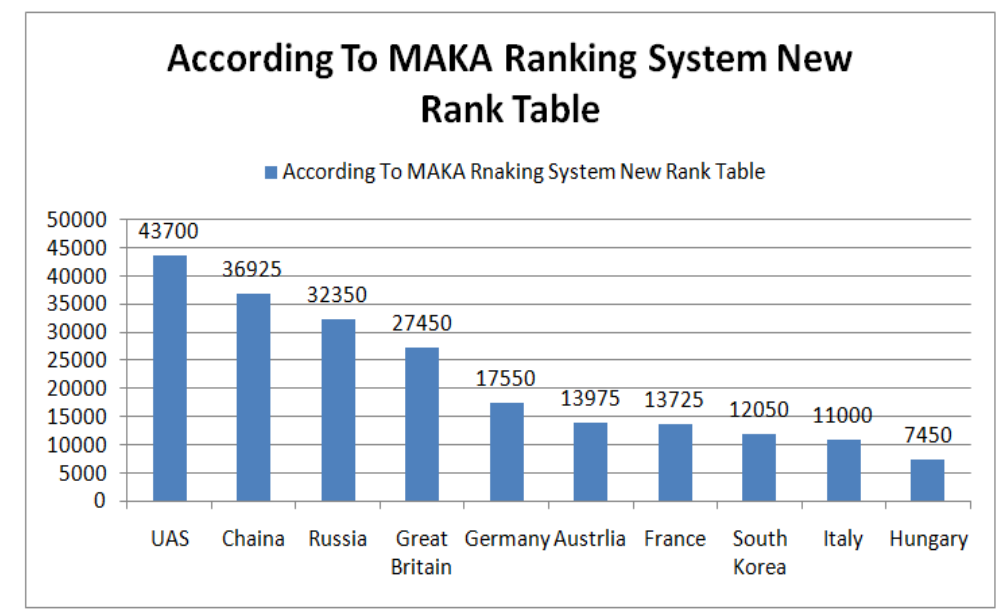

The result and findings described in this study examined the ranking system of top ten countries in the Olympic 2012 in regard to the MAKA ranking system.

\section{Discussion Of Finding}

1. Based on the MAKA system, the medal tally of USA team for individual game in the 2012 summer Olympic game bagged up 30700 points.

2. Based on the MAKA system, the medal tally of USA team for team game in the 2012 summer Olympic game bagged up 1300 points.

\section{Testing Of the Hypothesis}

It was hypothesized that there is change in the medal tally According to the MAKA ranking system, the result depicts that there is change in the ranking so the earlier stated hypothesis was accepted.

\section{Conclusions}

The following conclusions have been be drawn from the obtained results:

1. Based on the MAKA system, the medal tally of USA team for individual game in the 2012 summer Olympic game bagged up 30700 points.

2. Based on the MAKA system, the medal tally of USA team for team game in the 2012 summer Olympic game bagged up 1300 points.

3. Based on the MAKA system, the medal tally of china team for individual game in the 2012 summer Olympic game gained up 28600 points.

\section{Recommendations}

1. Further the study may be conducted on winter Olympic Games.

2. Further the study may be conducted on the comparison of the top ten countries of summer Olympic Games with bottom ten countries of summer Olympic Games.

\section{Recommendations}

1. Further the study may be conducted on winter Olympic Games.

2. Further the study may be conducted on the comparison of the top ten countries of summer Olympic Games with bottom ten countries of summer Olympic Games.

\section{Books}

\section{Bibliogrphy}

[1]. Bnoient Emonet,"Revisting Statistical Application in Soccer.' htt.//www.scibet.com/ articles/Vol.54,p.34,2000.

[2]. ChurilovL "Towards Fair Ranking of Olympics Achievements: The Case of Sydney 2000"Copumters and Operations Research archive, Elsevier Science Ltd. Oxford, UK Vol.33 , P. 2057-2082, 2006.

\section{Jouranls}

[3]. $\quad$ EckardE.Woodrow,"Is The Bowl Championship Series A Cartel? Some Evidence, Business School, University Of Colorado Denver", Denver, CO, USA,Journal, vol. 14 no. p.1 3-22, 2011.

\section{Miscellaneious}

[4]. De Mello Soares, 3rd IMA International Conference on Mathematics in Sport, 2011 "A Ranking for The Vancouver 2010 Winter Olympic Games Based on Copeland 2011. 